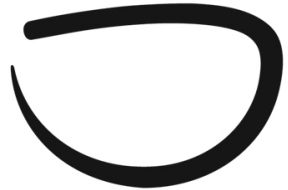

La Revue canadienne des études sur l'alimentation

\author{
Original Research Article
}

\title{
"Sometimes I feel like I'm counting crackers": The household foodwork of low-income mothers, and how community food initiatives can support them
}

\author{
Mary Anne Martin* \\ Trent University
}

\begin{abstract}
For women parenting on low incomes, there is a significant disparity between household foodwork standards and the resources with which to meet them. This study centres on the everyday foodwork experiences of low-income mothers and their engagement with community supports such as community food initiatives (CFIs). It helps address a research gap concerning the relationship between CFI participation and maternal household foodwork. The study employs multiple methods including semi-structured interviews, graphic elicitation and tours of local community food programs. By identifying a range of factors, strategies, and challenges in mothers' foodwork, the study elucidates some of the contradictory pressures that low-income mothers experience around foodwork. Some of these pressures are associated with meeting individualizing standards around being "good" mothers, "good" consumers and "good” food program participants. Efforts to meet these standards were seen through mothers' attempts to feed their children healthy and preferred food, exercise agency through market choices, and moderate their demands of community food programs. While more research is required regarding both mothers' actual participation in CFIs and CFI strategies to support them, the findings suggest that CFIs should incorporate low-income mothers' subjectivities into food programming.
\end{abstract}


Keywords: community food initiatives, foodwork, household food security, gender, labour, unpaid caring work

\section{Introduction}

In recent decades, a combination of discursive and material influences have positioned household foodwork standards in Canada further out of reach for some people, most notably low-income mothers of dependent children. Foodwork ${ }^{1}$ encompasses all the labour performed by household members to ensure their families ${ }^{2}$ are adequately fed. It is made possible through various resources, especially material ones such as money and food access. At the same time, foodwork is subjected to standards of health, child-raising, and good taste that are promoted through sources such as public health organizations (Ristovski-Slijepcevic, Chapman, \& Beagan, 2010), public education (Ristovski-Slijepcevic et al., 2010), and popular food literature (Julier, 2006). Although foodwork may reveal love, creativity, joy, and resistance, the standards that accompany these rewards are unequally distributed, particularly regarding gender (Allen \& Sachs, 2007; Brady, Gingras, \& Power, 2012) and more specifically, motherhood (Cairns \& Johnston, 2015).

The inaccessibility of foodwork standards suggests a need for greater supports for mothers, especially those living on low-incomes. However, some of the most recognizable sources of social support reveal significant limitations. For example, state-sponsored social assistance programs may be stigmatizing and provide insufficient resources (Power, 2005; Raphael, 2011), similar to the critiques about charitable food programs ${ }^{3}$ such as food banks (McIntyre, Tougas, Rondeau, \& Mah, 2016). The downloading of public social supports onto the shoulders of families (Armstrong, 2010; Luxton, 2010; Cossman \& Fudge, 2002) might strain the ability of family to provide support.

Other potential sources of support are community food initiatives (CFIs), which represent programs that are grounded in local community, provide alternatives to the dominant food system, foster social inclusion, and centre dignity in food access and food literacy. They include programs such as collective kitchens, good food box programs, gleaning programs, food literacy programs, and community gardens. The links between CFIs and mothers' household foodwork have, however, been understudied to date. This qualitative study based in Peterborough, Ontario, is an attempt to address this research gap while validating and elucidating the foodwork experiences of low-income mothers. It explores the everyday foodwork experiences of low-

\footnotetext{
${ }^{1}$ Although I recognize that work with food occurs in many contexts (e.g. domestic spaces, agriculture, retail), for the purposes of this article, "foodwork" is interchangeable with "household foodwork."

${ }^{2}$ I recognize that family members do not always reside together in a household and that household members are not always family members. However, for this article "household" and "family" are used interchangeably.

${ }^{3}$ By "charitable food programs," I am referring to those programs whose entire or almost entire purpose is to provide people with food free of charge (with little attention to meeting other needs) and whose access to that food comes largely through donations.
} 
income mothers and their engagement with community supports such as CFIs with a view towards helping CFIs better support mothers’ foodwork efforts.

\section{Household foodwork}

Although household foodwork in general places high demands on those responsible for it (DeVault, 1991; Van Esterik, 1999), the distribution of foodwork responsibility continues to reflect social organizations of power, including gender and class. In fact, despite a general reduction in home-cooked meals (DeVault, 1991; Julier, 2006), an increase in men's involvement in household food labour (Milan, Keown, \& Robles, 2011; Szabo, 2012), and a post-feminist discourse contending that gender inequality has largely been resolved (Cairns \& Johnston, 2015), a gendered disparity in household food labour still persists (Allen \& Sachs, 2007; Beagan, Chapman, D’Sylva, \& Bassett, 2008; DeVault, 1991; Parsons, 2016; Statistics Canada, 2009; Szabo, 2011) and is immersed in class relations (Allen \& Sachs, 2007; DeVault, 1991; LeBesco, 2001; Parsons, 2016).

The gendering of household foodwork practices is bound up in emotion. Indeed, since the word "caring" at once denotes an emotion (love), a personality trait, and the work of looking after people's needs, caring for loved ones becomes equated with caring about them (DeVault, 1991; Neysmith, Reitsma-Street, Baker Collins, \& Porter, 2004). Conversely, not tending to their needs comes to represent not caring about them and, in fact, is seen as being selfish (Cairns \& Johnston, 2015; DeVault, 1991). For women, especially mothers, this logic represents a potent equation. In fact, Cairns and Johnston (2015) argue that mothers' foodwork is propelled by the pursuit of positive emotions, such as pride, but also the avoidance of negative ones, such as guilt. Their emotional work of demonstrating love and devotion through food is, in effect, required by today's dominant standards of maternal foodwork (DeVault, 1991; Cairns \& Johnston, 2015; Parsons, 2016).

The pervasiveness and intensity of contemporary Western standards of motherhood have been captured and problematized by various researchers with the concept of the "good mother." For example, Goodwin and Huppatz (2010) see mothers as being assessed by both themselves and others based on their adherence with widely recognized, yet culturally and temporally variable, "good mother" (p. 1-2) standards of responsibility and appropriateness. Other researchers specifically link the good mother to caring through food. For instance, the employed mothers in research by Slater, Sevenhuysen, Edginton, and O'Neil (2011) were caught between aspirations to be "good mothers" (p. 409) who prioritized their family members' health and happiness through nutritious, tasty food, and "independent selves" (p. 410) focused on their own incomes and autonomy. For Cairns and Johnston (2015), the good mother expends significant emotional resources and effort as the "guardian of health and taste" (p. 74). She provides healthy food, socializes her children to make appropriate and healthy food choices, and protects her children from risk in the food system. Parsons (2016) likewise sees the good mother as 
prioritizing health and time expenditure (e.g., cooking from scratch) in food practices. Similarly, Ristovski-Slijepcevic et al. (2010) see the good mother as pressured to safeguard her children's health through the adoption of dietary guidelines that represent a narrow cultural interpretation of healthy eating.

Dominant foodwork standards of motherhood reflect a middle-class orientation that furthers their unattainability for mothers living on low incomes (Cairns \& Johnston, 2015; Parsons, 2016). And yet, despite the high foodwork standards to which all women who parent are held (Parsons, 2016), both gender and parenting status seem to contribute to mothers' risks of poverty ${ }^{4}$ and food insecurity, ${ }^{5}$ effectively hampering their foodwork, their market engagement, and their independence.

Household foodwork remains a gendered and maternalized activity requiring significant emotional and time expenditures. Women who parent are personally held to standards of good motherhood that demand a preoccupation with ensuring the health of their children through food. For mothers, such as those with few material resources, these standards are particularly inaccessible. What is less than clear in the literature, however, is how the good mother construct is specifically experienced by low income mothers in foodwork.

\section{Community food initiatives}

An understanding of the inaccessibility of maternal foodwork standards prompts an exploration of the ways in which low-income mothers envision, seek out, and use systems of support. A potential source of such support comes in the form of community food initiatives, which are grounded in local community, provide alternatives to the dominant food system, foster social inclusion, and centre dignity in food access and food literacy.

Several limits, however, have been identified by researchers regarding the possible benefits of participation in CFIs. The first regards the most fundamental barrier to household foodwork, food insecurity or the "inadequate or insecure access to food because of financial constraints” (Tarasuk, Mitchell, \& Dachner, 2016, p. 2). Because food insecurity is rooted in income insecurity, it is not surprising that participation in certain CFIs has been found to have little impact on lowering food insecurity (Collins, Power, \& Little, 2014; Engler-Stringer \& Berenbaum, 2007; Loopstra \& Tarasuk, 2013).

Second, there is a question regarding levels of CFI participation among low-income people. For example, Roncarolo, Adam, Bisset, and Potvin (2014) found that people living with greater vulnerability (as determined by food insecurity, health, civic engagement, education level and income level) were less likely to use "alternative” (p. 200) programs, such as community

\footnotetext{
${ }^{4}$ Female parents in Ontario are more likely than male parents to raise children on their own and to live in poverty when they do (Campaign 2000, 2016).

${ }^{5}$ The rate of food insecurity in Canada for the households of lone female parents with children under 18 years old is at least twice that of the other household types, including lone male parent households, that were considered by the cross-Canada food insecurity research group, PROOF (Tarasuk, Mitchell, and Dachner, 2016).
} 
gardens and collective kitchens, than "traditional” (p. 200) ones like food banks. Regarding community kitchen and food box programs, Loopstra and Tarasuk (2013) also found that nonparticipation was linked to a lack of program access (location or knowledge about) and an inability to work with the needs, desires, and schedules of families.

Third, in posing alternatives to dominant food systems, CFIs promote a "re-engagement with food” (Szabo, 2011, p. 548) that increases involvement in producing, accessing, and preparing food. However, calls for greater involvement with food may obscure the existing time demands on those who would do this work (Julier, 2006; Matchar, 2013; Szabo, 2011). Despite the potential for this re-engagement to augment the labour of those most responsible for household foodwork, the existing literature reveals little gender analysis regarding participation in CFIs themselves. Some research has found increased work on the part of women to inhibit engagement with community supported agriculture and farmers’ markets (Allen \& Sachs, 2007) and in the selection and use of local food (McIntyre \& Rondeau, 2011). More research is certainly needed on the role of gender, as CFIs might risk excluding people from participating and elevating labour expectations for those already responsible for foodwork.

Conversely, collective kitchen participants in the study by Engler-Stringer and Berenbaum (2007) described several benefits such as food variety and quality, greater dignity, and less distress. Additionally, Levkoe's (2006) study of a Toronto urban agriculture program that included community gardens suggested that community-based food initiatives might help to recast consumers as citizens, fostering civic engagement, lessons in democracy and a new sense of the collective which can all be applied towards greater social activism and change. Beyond just direct impacts on household foodwork, such benefits might help to foster the conditions for more equity around food access and foodwork.

So far, the literature shows little attention to the specific ways in which CFIs support household foodwork, especially among low-income mothers, although much of the research paints a picture of limited positive impact. It reiterates that CFIs cannot address food insecurity, an income-based problem, on their own. It also indicates some limits for CFIs in addressing issues of program access and fit, such as for low-income mothers who may be inhibited by greater food labour expectations. However, authors have also found some potential in CFIs to provide more indirect support, in the form of dignity and collectivity, which may help to foster more equity in foodwork. The literature described here suggests a need for further exploration into the ways in which low-income mothers actually engage with CFIs of different types, the barriers that prevent them from doing so, and the possible benefits that emerge from such participation.

\section{Methodology}

My methodological choices were intended to illuminate the day-to-day experiences of lowincome mother participants, contribute to program and policy development, and help CFIs better 
support the mothers' foodwork efforts. The data presented in this paper are part of a larger study addressing CFI perspectives and capacity, which included interviews with CFI service providers. While these interviews, along with CFI grey literature and my own involvement in Peterborough food system networks, provided valuable insights about the philosophies and workings of CFIs, the findings from that data set are outside the scope of this article and are given their own attention in my as-yet unpublished dissertational work.

This article draws largely on semi-structured interviews with 21 women who identified as living on low incomes in Peterborough City or County, and were raising at least one child under the age of 16. They were recruited through posters and contact with social services, relevant businesses, and local food networks. Four participants learned of the study from other participants. Because the reasons for non-participation in CFIs have been understudied (Loopstra \& Tarasuk, 2013), food program participation was deliberately left out as a criterion for joining the study.

In all, the women ranged in age from 19 to 47, with most (13 women) in their thirties. Over half of the participants (13 women) had completed some post-secondary education. All participants had at least one child living with them under the age of 16, but overall, their children at home ranged in age from four and a half months to 26 years old. Most (17) mothers had one or two children living at home although this extended to six children. One participant identified as Métis, one as First Nation, one as part Jewish, and one as mixed race. Two participants did not provide an ethnocultural background. The rest identified as Canadian, Caucasian, White and/or European descent. No participants identified as non-heterosexual/-straight although three did not provide a sexual orientation. Eight participants did not report any other adults in the household, eight lived with their children and a partner (and possibly other adults), and the rest lived with their children and adults who were not their partners.

All of the participants identified during recruitment as meeting the study's general criteria of living on low incomes. When asked in the interview about income level, one women did not respond, eight women disclosed a household monthly income below $\$ 2,000$ and ten disclosed a range between $\$ 2,000$ to $\$ 2,999$. For two participants, household monthly income was $\$ 3,000$ per month or above. This means that 18 women had household incomes below the Before-Tax Low Income Measure (Statistics Canada, 2016). Although two of the participants relied primarily on their own employment income, two on their partner's employment income, and one on both her partner's income and her own, most of the women relied primarily on some form of government income support.

In the interviews, the mothers were asked about all forms of foodwork for their households and any supports around this work. ${ }^{6}$ They were also asked to draw what a week in food looked like in their homes. Visual methods may allow participants to express what is difficult to put into words (Power, 2003) or express complex or emotionally connected thoughts

\footnotetext{
${ }^{6}$ Some parts of the guide format and questions were adapted from the interview guide of Lynn McIntyre and Krista Rondeau (2011) which has been described in detail in their previous publications (McIntyre, Thille, \& Rondeau, 2009). The guide was provided to me by Lynn McIntyre (Dec. 4, 2014).
} 
(Copeland \& Agosto, 2012). Participants' words and pictures were used to elaborate on each other, bringing clarity to the participants' perceptions and strength to the study's trustworthiness.

Once all the interviews were completed, the mothers were invited to participate in one of two tours of community food initiatives. In all, seven women participated in tours and six of them stayed after the tours to meet together with me to share their thoughts about ways the program might or might not fit for their families. For both the tours and the interviews with mothers, participants were provided flexibility around scheduling and location, and were offered refreshments and compensation for their time, childcare, and transportation. During the data collection process, I also used a reflection journal to help maintain my own awareness of issues of power and privilege in the study. The recordings from the participant mother interviews were transcribed using Express Scribe software. With the assistance of ATLAS.ti software, codes were applied to quotations and then refined. Memos were used to clarify the meaning of codes and to document thoughts and insights that developed throughout the process. The codes were analyzed to reveal patterns and broader themes. I provided participants the option to receive a copy of their interview transcripts but at this point, only two participants have requested and been sent their transcripts. The two recordings from the CFI tours were also transcribed. I sorted the feedback from the tours into themes and compared these findings with those from the interviews.

The (ongoing) dissemination of results through presentations and meetings with community food system actors is intended to inform service providers and policy makers about mothers' priorities and contribute to supportive policy and program changes. Feedback from these events so far has also informed my own thinking and helped to strengthen this research.

\section{Results}

Participants shared a range of factors that influenced their foodwork as well as the strategies and difficult compromises they used to ensure their families were adequately fed. The drawing by one participant, Alicia ${ }^{7}$ (Figure 1), provided an indication of the scope of these considerations, some of which related to health, social connections, money, body image, and love.

\footnotetext{
7 Pseudonyms have been used for all participants.
} 


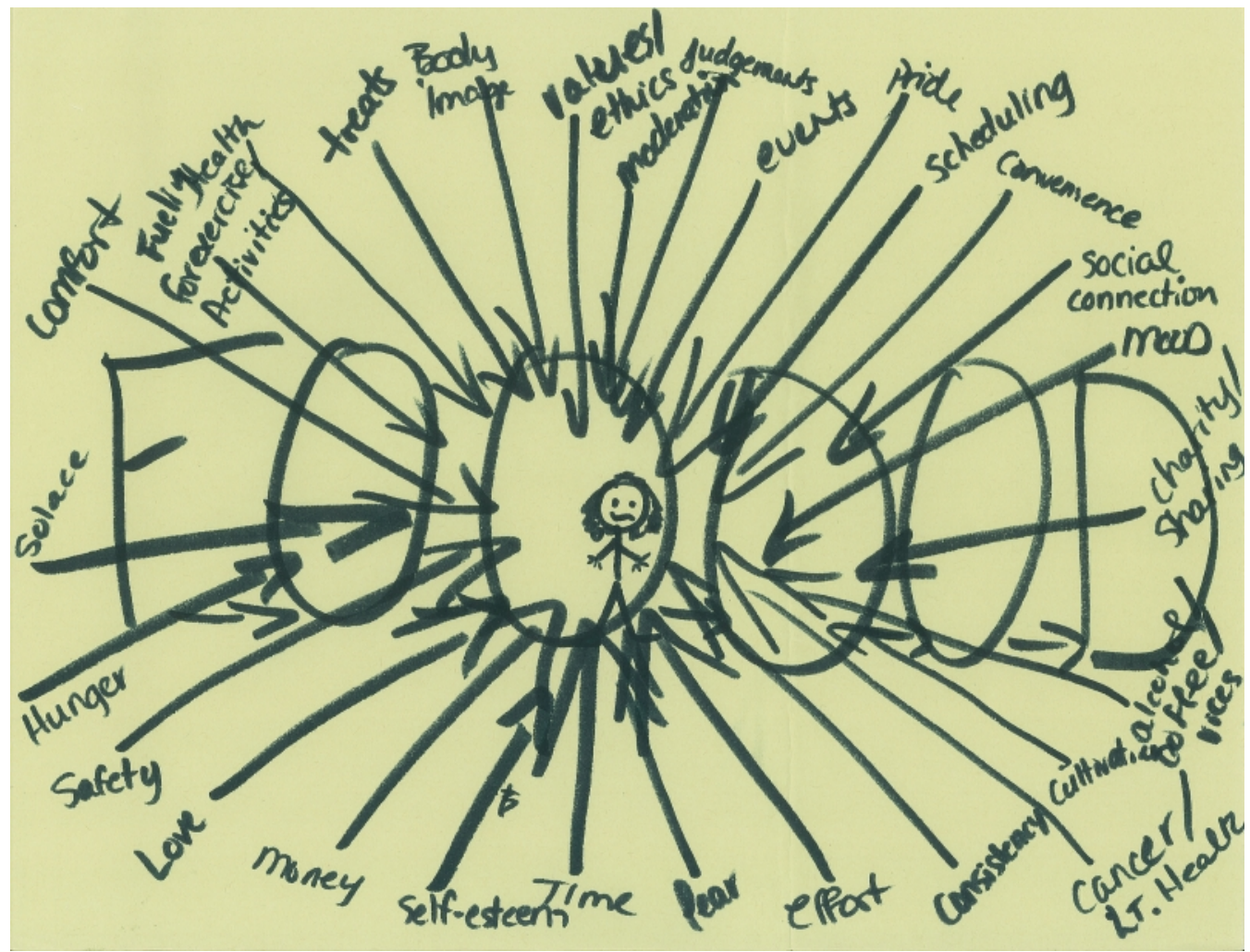

Figure 1: Drawing by Alicia

The women also spoke about their foodwork supports, both personal and programmatic. In an attempt to avoid biasing women's answers around specific programs, the interview guide included questions about what foodwork supports women used but not whether they used specific programs. However, 11 women still spoke of participating in at least one of the CFIs and 15 spoke of participating in a local food bank. Reasons given by multiple women for not participating in a CFI included a lack of knowledge about the programs and difficulty getting to them. A few also expressed discomfort with some aspect of a program while others had tried to access a CFI and were waiting to hear back. Yet, it was both the women's descriptions of their daily foodwork and their thoughts on programs that provided insights about their foodwork needs. Overall, the descriptions of both their foodwork and community supports around food revealed much love, cognitive labour, resourcefulness, and struggle. The following sections organize these findings in terms of the subjectivities that emerged, specifically the efforts to meet the standards of three main ideals, those of the "good mother," "good consumer," and "good food program participant.”

\section{The good mother}

Participants revealed a universal commitment to ensuring their children's health through food, a finding that was supported by other research that identified the good mother ideal (Cairns \& 
Johnston, 2015; Parsons, 2016). The women's focus on the health of their children ranged from current physical health to future physical and mental health, social adjustment, and selfsufficiency. They used strategies such as avoiding unhealthy food, mitigating food risks, teaching children about food, raising children to use healthy food habits, making food from scratch, and considering “expert” advice. However, the objective was largely pursued by incorporating healthy ${ }^{8}$ food (especially vegetables) into their households’ diets.

Frequently, mothers struggled to afford sufficient, healthy food. Some made difficult choices between necessary expenses or compromised their own food intake. Others acquired food in ways that compromised their dignity, integrity, or independence. Una found herself reluctantly monitoring her teenaged son's food intake, just to ensure that there would be enough food for the family in the coming days.

Una (35): I don’t like making him feel like a, a pig or anything but sometimes I'm like, “you just ate an hour ago.” (...) So sometimes I feel like, “OK, just eat something.” He’s a growing boy. You always hear about it so, ya sometimes I feel like I'm counting crackers.

Whereas Una demonstrated the tension that insufficient income can place on ensuring adequate food for her family, Melanie revealed another tension, between providing healthy food and food her child enjoyed.

Melanie (38): I want to keep him happy and not feeling like he has the worst mom ever because he has to eat an apple, you know? [laughs] (...) When I was a kid, (...) we went to school with sandwiches and apples and that was IT. So, I remember watching kids with all their yummy stuff being like, man! So, I want him to be happy in that sense, you know? So, [pause] But I have to feel like I'm doing it healthily so [laughs] so I try to buy the things that say, [bright advertising tone:] "Real Fruit Juice” and you know what I mean?

While raising healthy children motivated much of the women's foodwork, building connections with them and contributing to their happiness also played a significant role in this work. It was evident that Melanie was not just driven by the allure of positive emotions but also the avoidance of negative ones. She worried about her son viewing her as "the worst mom ever" for providing him healthy food that might risk his ability to fit in among his peers. Like Melanie, Theresa also showed how food provision was tied with her identity as a mother, but this time, through making food from scratch.

\footnotetext{
${ }^{8}$ Even so, their definitions of healthy food varied widely, from balanced meals to country food (for the two women who identified as having Indigenous backgrounds) to the inclusion/avoidance of specific food items to preferencing certain food origins (e.g. non-processed, local, GMO-free and/or organic food). As Kristen, 46, told me, “I don’t want any factory food.”
} 
Theresa (33): I hate to say it, but the food bank gives a lot of crap sometimes. So, I don't like to give them [her children] all that. I'd rather make their food. (...) I would rather make it for them because I make it FOR them so it makes me feel good that I'm making food for them (...) It's made with love.

For Theresa, cooking from scratch enabled her to provide healthier food and to demonstrate caring for her family. Not only was it important to some of the mothers that their children find nutrition and pleasure through food, but it was also important to some women, like Theresa, that they themselves were instrumental in this. This may reflect a pattern of women showing devotion through the investment of time to cook from scratch (Parsons, 2016). It may also be consistent with findings by Buck-McFayden (2015) that low-income women cooked from scratch to save money, something described in the next section.

Themes around sufficient, affordable, healthy food emerged when women spoke about CFIs. Some described the reassurance that predictable access to food from CFIs could offer, for example, from knowing that there would be a grocery gift card or good food box coming. Some participants also saw certain CFIs as offering food quality and a low-investment chance for their families to try new and healthy foods without the risk of wasting money on them. They did not express the same concern about a lack of healthy food options at CFIs that they did with regards to food banks. Sometimes participants, like Norah, found their parenting responsibilities impeded their access to community supports.

Norah (38): If these programs [CFIs] had childcare available, I'd definitely access all of them. I'd take advantage of every single one of them if they had childcare. Because it's the only obstacle I'm facing.

Some parents also saw CFIs as offering a chance for their children to learn about food or for mothers to connect with their children around food.

\section{The good consumer}

Most of the participants' approaches to foodwork reflected an emphasis on affordability and securing enough food for their households. These approaches included: optimizing food shopping practices; accessing food through food banks and other community food programs; receiving or bartering resources from/with people in their lives; ensuring enough food for later by preparing food ahead of time, ensuring leftovers, or preserving; and using equipment such as freezers or slow cookers.

Specific strategies aimed to mitigate food costs through shopping practices constituted a strong thread in our conversations. These included the use of specific grocery stores, coupons, price matching, flyers, grocery lists, generic brands, budgets, bulk shopping, and grocery sale phone apps. Even though market transactions and the exercise of choice were constrained by low 
incomes, the women spoke frequently about their efforts to spend wisely, a practice that has been shown in the literature to earn cultural capital. ${ }^{9}$ Indeed, Beagan et al. (2015) found that, when purchasing power is constrained, thriftiness can be the simplest way for those who are "closer to necessity" (p. 142) to distinguish themselves as worthy.

Not only does this wide range of shopping practices and other food access strategies begin to illustrate the importance of affordability and the extra foodwork that living on a low income can entail, but it also shows the women's emphasis on individualized and market-based solutions for addressing household food shortages. As an example, here is an exchange with Una about her drawing of a week of food in her household.

Author: Anything [else] that's important?

Una (35): [pause] Coupons. (...)I'll do the free milk coupon. That's very important to me. (...) They actually give you one coupon per child so it ends up being THREE free bags of milk which is like amazing.

For Una, gift cards provided by community food projects were so important that she highlighted them in her drawing (Figure 2) and discussion. Gift cards represented one way in which the desire to have normalized market engagement presented itself among the women, especially in discussions of community supports. In fact, about a third of participants raised the importance of the gift cards offered by some community programs. The cards provided benefits such as the choice of what and when to buy, as well as being lighter to carry than food donations.

Figure 2:

Drawing by Una

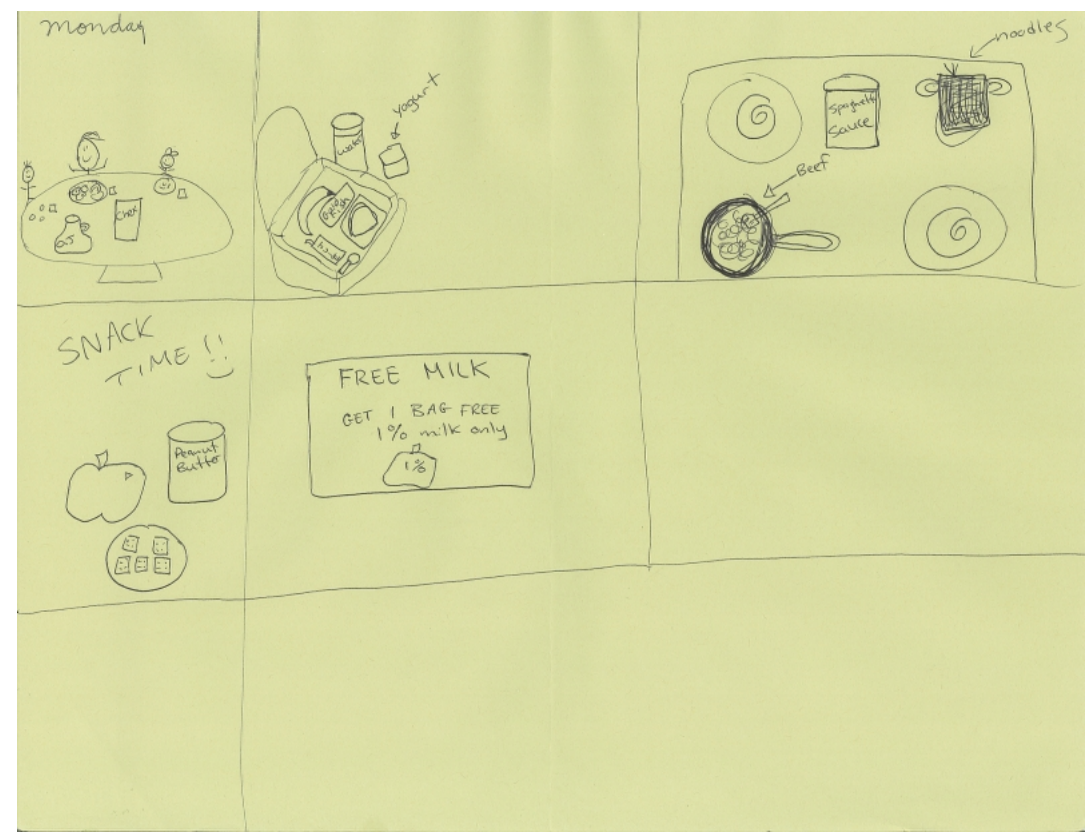

\footnotetext{
${ }^{9}$ Cultural capital (skills, knowledge, credentials, comfort with certain knowledge/practices) is one of Pierre Bourdieu's forms of capital (including social, cultural and symbolic capital) that Beagan et al. (2015) illustrate as important in distinguishing "good" from "bad" people through their food practices.
} 
Here, Olivia described another facet of programs that appealed to her.

Olivia (38): The next best food bank at this point is [food bank name] because it's more of a "shopping experience." I get 50 dollars.

Not only did women express the importance of consumer transactions, but Olivia also showed the importance of simply feeling like she is shopping. Low-income people, hampered in their ability to fulfill capitalism's dual mandates of earning and spending, can be marked as "flawed consumer[s]" (Power, 2005, p. 651). Women spoke often of the costs that could be incurred or, more often, defrayed by CFI participation A few participants spoke about the opportunity that saving money on food at a CFI could allow for them to purchase food in other ways. For the most part, the women who participated in JustFood, a local twice-monthly food box program that offers a sliding fee range, found it to be economical. Although some women used informal and collective methods of acquiring food, the mothers often showed efforts to be "good consumers" who use market engagement, make their own choices, and spend money wisely.

\section{The good food program participant}

In discussing their engagement with community food programs, both CFIs and food banks, participants revealed strong thoughts about personal conduct and values. Notably, despite their focus on health and choice, participants were still careful to temper their demands of food banks.

Melanie (38): For every complaint people make about the food banks and what they have in there, they do provide you alternatives, you just have to want them.

Melanie’s comment here echoed the admonition that “beggars can't be choosers.” Her words reflected the way in which some participants felt compelled to act as good food program participants by adjusting their demands around what charitable programs can provide. The following excerpt showed Norah's internal struggle over what she should feel entitled to demand from food banks.

Norah (38): I find that both food banks have a lot of junk food. (...)

And they try to (...) give you more than you'd normally get of something else, right? I don't know, beggars can't be choosers. But I feel that like, I don't know, junk food's obviously not nutritious or really good in any way, except for kids but I mean some people probably LOVE the fact that they get junk food, [laughing] right? (...) I'd rather have something more nutritious. (...) I feel bad saying no when I'm there but I do. I've gotten better. If I don't want something, I will say, "No thank you." I used to just take 
everything because I was too afraid to say no. I didn’t want to feel ungrateful or rude.

Here Norah exhibited a tension between the good mother and the good food program participant ideals. On the one hand, she was seeking out sufficient, healthy, and desired food for her family. Yet Norah also illustrated the pressure on food bank participants to temper their demands (in this case by accepting unhealthy food), to not expect to exercise choice, and to not seem ungrateful. While such concerns emerged more with food banks, Alicia showed a similar response when she was not called back by a CFI.

Alicia (29): I tried to call but nobody ever called me back so rather than keep persistent about it, because that felt really needy and wrong, I just didn’t call back 'cause if they didn't call me back, then they're probably full (...) and I don't really want to be a nuisance and I certainly don't want to look a gift horse in the mouth by being demanding, right? [a bit later, after my response] (...) And sometimes I just feel guilty because I know, I know that there are people in way worse situations than me and I don't want to take their spot.

After not receiving a call back, Alicia avoided calling the program again for fear of being “needy," “wrong,” ungrateful, and “demanding.” This questioning of her own dependence and worthiness illustrated an engagement with the standards of good food program participants who temper their demands, do not take more than they should deserve, and express gratitude for supports offered. Another dimension of this ideal that Alicia, like Norah and other mothers demonstrated, was a concern for others who were in greater need than themselves. ${ }^{10}$ Rather than this kind of empathy itself, it is the compulsion that the mothers felt to situate (and dismiss) their own family food needs within a hierarchy of others' needs that I find problematic. Certainly, all programs cannot realistically meet the needs of all people. However, such comparisons on the part of participants echo the neoliberal logic of austerity and scarcity, the contention that there is not enough to go around. They show a departure away from guaranteed, universal food access and towards needs-based food provision. In effect, they problematize the perceived selfishness of certain low-income people rather than the inadequacy of charity-based programs or, more importantly, of government enactment of guarantees of food security. As an example, Melanie spoke about her participation in food banks.

Melanie (38): Like I said, I try to go every OTHER month so that I'm not taking advantage. I have, I have guilt. [laughs] I don't like to take advantage of things if I don't HAVE to so I try to keep the food banks as a necessity not, like I don't want to abuse it. Like I do know some people who would rather go to the food banks so

\footnotetext{
${ }^{10}$ Power (2005) found that the low-income lone mothers in her study also made distinctions between themselves and those they felt were worse off. She saw these comparisons as a way for the women to justify their hardships and lower their household expectations but also as evidence that the women recognized their hardships as such.
} 
they can blow their money on stupid things, you know? And I just, I don't agree with that. I can’t allow myself to conduct my life that way.

Melanie showed pride in her ability to uphold certain principles. However, despite their personal struggles around perceptions of dependence and worthiness, participants such as Melanie at times used this same moralizing logic regarding other people living on low incomes, particularly those who engaged with food banks. In doing so, the women suggested that these individuals would take too much, spend unwisely, not be grateful for the supports they received, or not make enough of an effort towards healthy feeding practices or productive use of time. In demonstrating a distance from such descriptions, participants also echoed the ideals of the good mother, good consumer, and good food program participant.

Interestingly, participants did not generally speak about food banks’ ability to provide more than material goods such as food, and sometimes personal and cleaning supplies or holiday gifts. It was only regarding CFIs that the women spoke about developing friendships, (e.g., the one mother who spoke of having used a community garden had hoped for more community connectedness in that experience), connecting with their children through food activities, learning about growing, preserving, and preparing food, and helping farmers, other people, and the environment through program participation.

Overall, the participants' foodwork narratives were permeated with an engagement with constructions of good mothers, good consumers, and good food program participants. As the women were trying to use food to raise healthy and happy children, they were also trying to belong in a consumer society and, when this was difficult, trying to engage with food programs in ways that might assure both food resources and dignity. These sometimes-competing pressures suggest a need for more exploration into the role that alternative supports, like CFIs, might play.

\section{Discussion and conclusion}

This study considered the inaccessibility of maternal foodwork standards for low-income mothers by exploring their daily foodwork practices and their engagement with community supports such as CFIs. It was designed to address a lack of scholarly work on the role that CFIs might play in helping to support this group of mothers in their foodwork. The study found that the women's foodwork represented a complex mix of bare necessity, duty, love, struggle, the desire for connection, and the influence of dominant messages about superior food practices. Their foodwork also involved great effort and resourcefulness.

Participants' range of practical and ideological considerations suggested that they engaged with three connected ideals: the good mother, the good consumer, and the good food program participant. Consistent with previous research, this study found women pursued the ideal of the good mother by assuming primary responsibility for using food to raise healthy and 
happy children (Parsons, 2016; Ristovski-Slijepcevic et al., 2010; Slater et al., 2011). It also found mothers responding to the construct of the "flawed consumer" (Power, 2005, p. 651) by attempting to be good consumers and, when this was not possible, to be undemanding food program participants. I found that women tried to be good consumers through market engagement, choice, and spending wisely. Good food program participants were careful to temper their demands, never take advantage of community supports, and demonstrate gratitude for any supports offered.

Participants' foodwork, like that of the mothers in research by Cairns and Johnston (2015), was influenced by positive and negative emotions that were tied to their identities as mothers. In fact, the power of emotion (e.g., pride, love, guilt, shame) to drive the mothers' pursuit of all three ideals (good mother, good consumer, and good food program participant) suggests that the women were not only trying to be good at these roles, but were trying to be good through their efforts to meet these ideals. This embodiment of maternal morality is recognized by Goodwin and Huppatz (2010) who stated, "This in essence is the power of the good mother: mothers want to be good” (p. 7). These emotions belie the moral regulation of lowincome mothers (Little, 1998; Power, 2005). These efforts towards and ways of being good as mothers, consumers, and program participants were necessary for ensuring the well-being (health, happiness, belonging, and food access) of their families. In essence, the women's attempts to be "good" highlight the provisionality of such conditions of well-being.

The findings are aligned with other researchers' perceptions that the good mother, perhaps the most aspirational of the three ideals (Parsons, 2016), has a middle-class orientation that places maternal standards of foodwork further out of reach for low-income mothers (Cairns \& Johnston, 2015; Parsons, 2016). In its specific exploration of low-income mothers' practices, however, this research revealed that participants also aspired towards a good consumer ideal that helped to cement this unattainability by emphasizing the women's limits as earners and spenders. This good consumer exercises power in the world through market engagement, choice, and spending wisely. Although their spending and choice were constrained, consistent with the understandings of Beagan et al. (2015), the participants demonstrated greater agency here through thriftiness. Constraints around purchasing led participants to seek food access in other ways. In doing so, the women contended with the third, and least aspirational, ideal. This one, the good food program participant, is careful to temper her demands, never take advantage of community supports, and demonstrate gratitude for any supports offered. This ideal is unique to those who are compelled to use food programs because of inadequate incomes- and are therefore deemed “dependent." It de-normalizes non-market means of acquiring food in the community and rests on assumptions of scarcity. However, all three of the ideals valorize self-sufficiency (in the kitchen, marketplace, community), reflecting the construction and denigration of a narrow version of dependence, one that neglects the complexity and interdependence of caring work (Brodie, 1995; Duffy, 2011).

The consideration of the ideals of the good mother, good consumer and good food program participant may prove useful to CFIs for addressing the foodwork challenges of women 
who are parenting children while living on low incomes. Beyond addressing logistics, such as childcare and program access, this preliminary research suggests that CFIs should focus on healthy, enjoyable, and often mother-prepared food, as well as affordability, choice, and opportunities for market engagement. Further, it suggests sensitivity around the ways in which mothers may embody dependence and austerity narratives that dictate that they should be grateful for supports and not take advantage of them. It also suggests the importance of belonging, especially in a consumer-based culture. Through providing welcoming atmospheres, building alternative narratives around poverty, and building opportunities for social inclusion, CFIs may help cultivate a sense of belonging. However, through a focus on collective practices and the active inclusion of marginalized people, CFIs may also unsettle prominent assumptions about radical individualism, consumerism, and dependence, in the process perhaps challenging the constraints of good mother, consumer and food program participant ideals. The findings suggest the need to disrupt these ideals as well as disrupting the gendered and classed organizations of power that support them. On a broad scale, they also point to the need to address the income insecurity and related food insecurity that hamper and complicate efforts to ensure families are adequately fed.

The sample for this study may have represented women who were particularly willing to talk about their foodwork stories. The sample also was relatively homogeneous in several ways. In future research, important insights may be gleaned by connecting more deliberately with: mothers who expressly do not like foodwork; young, racialized, new immigrant and/or LGBTQ mothers; as well as a diversity of fathers, to explore their foodwork and the ways in which it engages with CFIs.

While there has been some scholarly attention to CFI engagement, for example around participation levels and impacts on food insecurity, overall, little research has explored the relationship between CFIs and household foodwork. Further study is required regarding the extent to which CFIs may, in fact, assist with closing the gap between foodwork standards and resources, especially for mothers living on low incomes. While more research is necessary, especially regarding the ways CFIs engage with this population, this study suggests some merit in incorporating maternal subjectivities into CFI programming.

\section{References}

Allen, P., \& Sachs, C. (2007). Women and food chains: The gendered politics of food. International Journal of Sociology of Food and Agriculture, 15(1), 1-23. http://ijsaf.org/archive/15/1/allen_sachs.pdf

Armstrong, P. (2010). Neoliberalism in action: Canadian perspectives. In S. Braedley and M. Luxton (Eds.), Neoliberalism and everyday life (pp. 184-201). Montreal-Kingston: McGill-Queens University Press. 
Beagan, B., Chapman, G., D’Sylva, A., \& Bassett, B.R. (2008). 'It's just easier for me to do it': Rationalizing the family division of foodwork. Sociology, 42(4), 653-671.

Beagan, B., Chapman, G., Johnston, J., McPhail, D., Power, E., M., \& Vallianatos, H. (2015). Social class trajectories in Acquired tastes: Why families eat the way they do (pp. 135160). Vancouver: UBC Press.

Brady, J., Gingras, J., \& Power, E. (2012). Still hungry: A feminist perspective on food, foodwork, the body and food studies. In M. Koc, J. Sumner and A. Winson (Eds.), Critical perspectives in food studies (pp. 122-135). Don Mills, Ontario: Oxford University Press.

Brodie, J. (1995). Politics on the margins: Restructuring and the Canadian women's movement. Halifax: Fernwood Publishing.

Buck-McFadyen, E.V. (2015). Rural food insecurity: When cooking skills, homegrown food, and perseverance aren’t enough to feed a family. Canadian Journal of Public Health, 106(3), 140-146.

Cairns, K., \& Johnston, J. (2015). Food and femininity. London: Bloomsbury Academic.

Campaign 2000. (2016). Let's do this, let's end child poverty for good: 2015 Report card on child and family poverty in Ontario. Retrieved from: http://campaign2000.ca/wpcontent/uploads/2016/08/Ontario2015Report.pdf

Collins, P. A., Power, E. M., \& Little, M. H. (2014). Municipal-level responses to household food insecurity in Canada: A call for critical, evaluative research. Canadian Journal of Public Health, 105(2), e138-41.

Copeland, A.J., \& Agosto, D.E. (2012). Diagrams and relational maps: The use of graphic elicitation techniques with interviewing for data collection, analysis, and display. International Journal of Qualitative Methods, 11(5), 513-533.

DeVault, M.L. (1991). Feeding the family: The social organization of caring as gendered work. Chicago: University of Chicago Press.

Duffy, M. (2011). Making care count: A century of gender, race, and paid care work. Piscataway, New Jersey: Rutgers University Press.

Engler-Stringer, R. \& Berenbaum, S. (2007). Exploring food security with collective kitchens participants in three Canadian cities. Qualitative Health Research, 17(1), 75-84.

Fudge, J., \& Cossman, B. (2000). Introduction: Privatization, polarization and policy: feminism and the future. In B. Cossman and J. Fudge (Eds.), Privatization, law and the challenge to feminism (pp. 3-37). Toronto: University of Toronto Press. 
Goodwin, S., \& Huppatz, K. (2010). (Introduction) The good mother in theory and research: An overview. In S. Goodwin and K. Huppatz (Eds.) The good mother: Contemporary motherhoods in Australia (pp. 1-24). Sydney, Australia: Sydney University Press.

Julier, A. P. (2006). Hiding gender and race in the discourse of commercial food consumption. In A. Avakian and B. Haber (Eds.), From Betty Crocker to feminist food studies: Critical perspectives on women and food (pp. 163-184). Amherst, Massachusetts: University of Massachusetts Press.

LeBesco, K. (2001). There's always room for resistance: Jell-o, gender, and social class. In S. Innes (Ed.), Cooking lessons: The politics of gender and food (pp. 129-150). Lanham, Maryland: Rowman \& Littlefield Publishers, Inc.

Levkoe, C. (2006). Learning democracy through food justice movements. Agriculture and Human Values, 23(1), 89-98.

Little, M. (1998). No car, no radio, no liquor permit: The moral regulation of single mothers in Ontario, 1920-1997. Toronto: Oxford University Press.

Loopstra, R., \& Tarasuk, V. (2013). Perspectives on community gardens, community kitchens and the good food box program in a community-based sample of low-income families. Canadian Journal of Public Health, 104(1), e55-9

Luxton, M. (2010). Doing neoliberalism: Perverse individualism in personal life. In Susan Braedley and Meg Luxton (Eds.), Neoliberalism and everyday life (pp. 163-183). Montreal-Kingston: McGill-Queens University Press.

Matchar, E. (2013). Homeward bound: Why women are embracing the new domesticity. New York: Simon \& Schuster.

McIntyre, L,. \& Rondeau, K. (2011). Individual consumer food localism: A review anchored in Canadian farmwomen's reflections. Journal of Rural Studies, 27(2), 116-124.

McIntyre, L., Thille, P., \& Rondeau, K. (2009). Farmwomen’s discourses on family food provisioning: Gender, health, and risk avoidance. Food and Foodways, 17(2), 80-103.

McIntyre, L., Tougas, D., Rondeau, K., \& Mah, C.L. (2016). “In”-sights about food banks from a critical interpretive synthesis of the academic literature. Agriculture and Human Values, 33(4), 843-859.

McKeen, W. (2004). Money in their own name: The feminist voice in poverty debate in Canada, 1970-1995. Toronto: University of Toronto Press Incorporated. 
Milan, A., Keown, L., \& Robles, C. (2011). Families, living arrangements and unpaid work. Women in Canada: A gender-based statistical report. (Component of Statistics Canada Catalogue no. 89-503-X) Retrieved from: http://www.statcan.gc.ca/pub/89-503x/2010001/article/11546-eng.pdf

Miller, T. (2011). Making sense of fatherhood: Gender, caring and work. Cambridge: Cambridge University Press.

Neysmith, S., Reitsma-Street, M., Baker Collins, S., \& Porter, E. (2004). Provisioning: Thinking about all of women's work. Canadian Women's Studies, 23(3/4), 192-8.

Parsons, J. (2016). When convenience is inconvenient: 'Healthy' family foodways and the persistent intersectionalities of gender and class. Journal of Gender Studies, 25(4), 382-397.

Power, E. (2005). The unfreedom of being other: Canadian lone mothers' experiences of poverty and 'life on the cheque'. Sociology, 39(4), 643-660.

Power, E. (2003). De-centering the text: Exploring the potential for visual methods in the sociology of food. Journal for the Study of Food and Society, 6(2), 9-20.

Raphael, D. (2011). Poverty in Canada: Implications for health and quality of life, second edition. Toronto: Canadian Scholar’s Press Inc.

Ristovski-Slijepcevic, S., Chapman, G., \& Beagan, B. (2010). Being a 'good mother': Dietary governmentality in the family food practices of three ethnocultural groups in Canada. Health, 14(5), 467-483.

Roncarolo, F., Adam, C., Bisset, S., \& Potvin, L. (2015). Traditional and alternative community food security interventions in Montreal, Quebec: Different practices, different people. Journal of Community Health, 40(2), 199-207.

Slater, J., Sevenhuysen, G., Edginton, B, \& O'neil, J. (2012). 'Trying to make it all come together': structuration and employed mothers' experience of family food provisioning in Canada. Health Promotion International, 27(3), 405-15.

Statistics Canada. (2016). Table 3.2 Low-income measures thresholds (LIM-AT, LIM-BT and LIM-MI) for households of Canada, 2010. Retrieved from: https://www12.statcan.gc.ca/nhs-enm/2011/ref/dict/table-tableau/t-3-2-eng.cfm

Statistics Canada. (2009). Time spent on various activities, by sex. Retrieved from: http://www.statcan.gc.ca/tables-tableaux/sum-som/101/cst01/famil36b-eng.htm

Szabo, M. (2012). Foodwork or foodplay? Men’s domestic cooking, privilege and leisure. Sociology, 47(4), 623-638. 
Szabo, M. (2011). The challenges of "Re-engaging with Food”: Connecting household patterns and gender relations to convenience food consumption in North America. Food, Culture and Society, 14(4), 547-566.

Tarasuk, V., Mitchell, A., \& Dachner, N. (2016). Household food insecurity in Canada, 2014. Toronto: Research to identify policy options to reduce food insecurity (PROOF). Retrieved from http://proof.utoronto.ca

Van Esterik, P. (1999). Gender and sustainable food systems: A feminist critique. In M. Koc, R. MacRae, J. Welsh, and L.J.A. Mougeot (Eds.), For hunger-proof cities: Sustainable urban food systems (pp. 157-161). Ottawa: International Development Research Centre. 